\title{
RESEARCH
}

\section{Evidence of a Predisposing Locus to Bipolar Disorder on Xq24-q27.1 in an Extended Finnish Pedigree}

\section{Petra Pekkarinen, ${ }^{1,3}$ Joseph Terwilliger, ${ }^{2}$ Per-Erik Bredbacka, ${ }^{1}$ Jouko Lönnqvist, ${ }^{1}$ and Leena Peltonen ${ }^{1}$}

\author{
${ }^{1}$ Departments of Human Molecular Genetics and Mental Health, National Public Health Institute, \\ Helsinki, Finland; ${ }^{2}$ Wellcome Trust Center for Human Genetics, University of Oxford, England
}

\begin{abstract}
An X-chromosomal predisposing locus to manic-depressive illness has been suggested since 1969 on the basis of the cosegregation of this trait in some families with phenotypic markers, such as color blindness, the glucose-6-phosphate dehydrogenase deficiency, and the coagulation factor IX deficiency. However, the conclusive evidence and the exact location of the putative X-chromosomal locus have remained controversial. We report here a linkage between DNA markers near the coagulation factor IX gene and bipolar disorder in an extended pedigree rising from the genetically isolated population of Finland. A distinct chromosomal haplotype covering a 20-cM region on Xq24-q27.1 could be demonstrated to segregate with bipolar disorder. These findings should encourage research groups to study extended family materials with $\mathrm{Xq} 24-q 27.1$ markers to finally resolve the question of the X-chromosomal linkage of bipolar disorder.
\end{abstract}

Bipolar disorder (BP) belongs to a group of affective disorders, which are psychiatric illnesses causing abnormal mood. Bipolar disorder is characterized by episodes of mania (BPI) or hypomania (BPII) and depression. During the episodes, patients experience changes in sleep, appetite, and sexual behavior and abnormalities of endocrine and chronobiological systems. BP aggregates in families, and, in addition to BP, these families frequently show cases of unipolar disorder and schizoaffective disorder (Weissman et al. 1984; Winokur et al. 1995). These three seem to represent different disorders, but they probably share some etiological factors. The lifetime prevalence of $\mathrm{BP}$ is $0.6 \%-1.2 \%$ and it is not influenced by sex or race (for review, see Goodwin and Jamison 1990). The onset of the disorder typically occurs at young adulthood and results in impaired interpersonal, social, and occupational functioning. As many as one-third of the patients have chronic symptoms and evidence of social decline (for review, see Goodwin and Jamison 1990).

The etiology of BP is unknown, but twin studies have evidenced the significance of ge-

\footnotetext{
${ }^{3}$ Corresponding author.
}

E-MAIL petra.pekkarinen@ktl.fi; fAX 35804744480. netic factors in predisposition to the disorder (for review, see Nurnberger and Gershon 1992). Even so, no success has yet been reached in identifying specific susceptibility genes to BP because of problems commonly encountered in the genetic analyses of complex diseases, such as unknown mode of inheritance and unclear phenotype (O'Donovan and Owen 1992). Many investigators have tried to locate the susceptibility genes to BP by classical linkage analyses. One chromosomal region repeatedly suggested to be linked to $\mathrm{BP}$ is Xq26.3-q28 containing the color-blindness (CB) and glucose-6-phosphate dehydrogenase (G6PD) loci on Xq28 (Reich et al. 1969; Mendlewicz et al. 1972, 1979, 1980; Mendlewicz and Fleiss 1974; Baron 1977; Gershon et al. 1980; Del Zompo et al. 1984; Baron et al. 1987) and the coagulation factor IX locus (F9) on Xq26.3 (Mendlewicz et al. 1987; Craddock and Owen 1992; Gill et al. 1992; Lucotte et al. 1992; Jeffries et al. 1993) (Fig. 1). The linkages to both of these regions, Xq28 (Gershon et al. 1979; Berrettini et al. 1990) and Xq26.3 (Gejman et al. 1990; Bredbacka et al. 1993; De bruyn et al. 1994), have also been rejected by many investigators. In addition, the linkage data have been challenged by a significant amount of criticism raising issues, such as hidden recombinants remaining undetected because of the low informativeness of the pheno- 


\section{PEKKARINEN ET AL.}

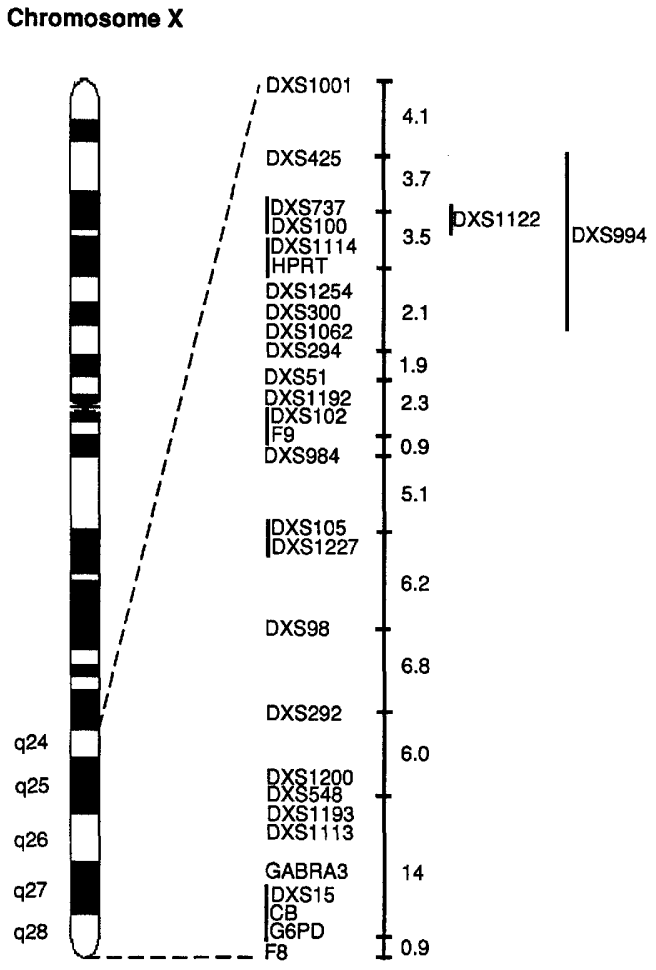

Figure 1 The order of the markers on Xq24-q28. Order is based on the report from the Fifth International Workshop on Human X Chromosome Mapping (Willard et al. 1994). Genetic distances are from Wang and colleagues (1994). The location of the marker DXS1122 is uncertain because it was only recently described (Donnelly et al. 1994). Also, the location of the marker DXS994 is unresolved, because it has been physically mapped between the markers DXS425 and DXS737 (Willard et al. 1994), but genetically it was localized more distally between the markers DXS100 and DXS1062 (Donnelly et al. 1994; Gyapay et al. 1994; Wang et al. 1994). The approximate locations of these markers are shown by a line at right of the ordered markers. Markers located within a 1-cM distance from each other are indicated by a line at left. Numerals between the markers are intermarker distances in centimorgans.

typic markers like $\mathrm{CB}$ and the G6PD deficiency (Baron et al. 1993), the possibility for ascertainment bias when ascertaining doubly ill probands (Gershon and Matthysse 1977), and the absence of evidence of the X-chromosomal transmission of manic-depressive illness (Hebebrand 1992).

The Finnish population has been isolated for several thousand years owing to geographical and linguistic reasons (for review, see de la Chapelle 1993). This kind of isolated population should be highly useful in genetic studies of complex diseases because of the founder effect, which restricts the number of the original predisposing mutations. We have studied one extended pedigree (P101), which rises from the genetically isolated population of Eastern Finland and demonstrates 16 affectively ill individuals (10 bipolar, 1 schizoaffective, and 5 recurrent unipolar) and report here evidence of linkage between bipolar and schizoaffective disorders and the markers on Xq24-q27.1.

\section{RESULTS \\ Linkage Analyses in Pedigree P1OI}

The X-chromosomal markers were studied as part of a genome screen for susceptibility genes in Pedigree P101. At that stage, -80 markers on chromosomes $3-5,9,11,13,15,18-22$, and $X$ had been analyzed.

Results of the two-point linkage analyses under the single major locus (SML) and affecteds only (AO) models (Table 5, below) and the most stringent diagnostic category $\mathrm{A}$ are presented in Table 1A. Under the SML model, a lod score of 3.54 was obtained to the marker DXS994 on $\mathrm{Xq} 24-\mathrm{q} 26$ at $\theta=0.0$. The linkage analyses to the same marker under the $\mathrm{AO}$ model resulted in a lod score of 2.17 at $\Theta=0.0$. Under both models, the surrounding markers on an 20 -cM chromosomal region revealed positive lod scores peaking at 2.9 (Table 1A). Under diagnostic category B, the linkage analyses resulted in less positive lod scores at higher recombination fractions with a maximum lod score of 2.21 to the marker DXS994 at $\theta=0.10$ (Table 1B). Under diagnostic category $C$, linkage analyses under the SML model resulted in negative lod scores except for markers DXS300 and DXS984, which gave positive lod scores of 0.70 and 0.74 at the $\theta=0$, respectively, and linkage analyses under the AO model resulted in uninformative positive lod scores with a maximum of 0.71 to the marker DXS984 at the $\theta=0$ (data for category C not shown). Linkage analyses with the markers outside the Xq24-q27 chromosomal region resulted in negative lod scores under both models and the three diagnostic categories with the exception of GABRA3, which remained uninformative.

To evaluate the probability to obtain equally high lod scores owing to chance alone, simulation analyses under no linkage were performed. Five thousand replicates of the pedigree under 
Table 1. Results from the linkage analyses

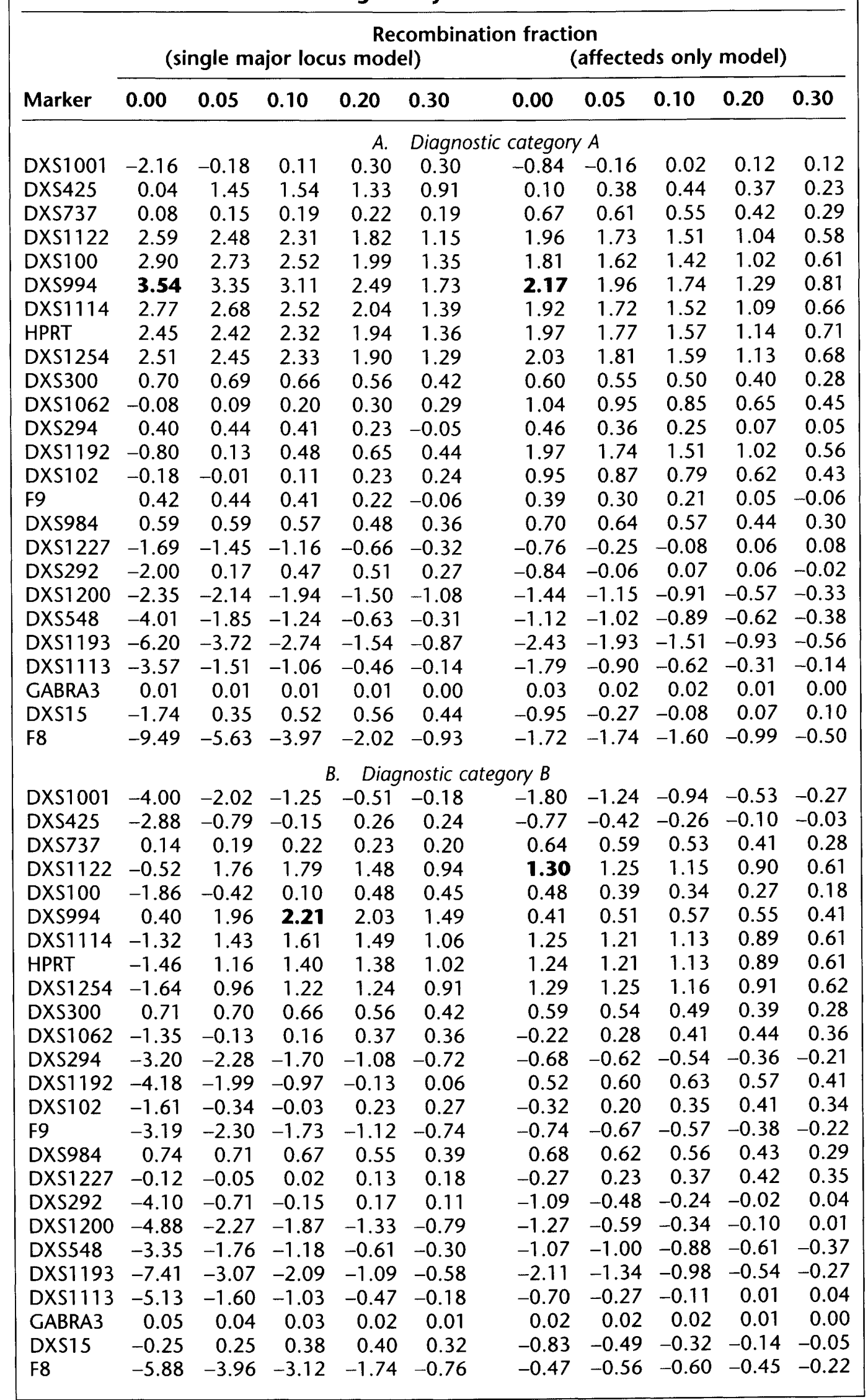

the assumption of an $\mathrm{X}$-chromosomal marker with equal allelic number and frequenc i e s t o DXS994 (four alleles; allele frequencies of $0.03,0.25$, 0.29 , and 0.43 ) a t $\Theta=0.5$ were simulated usi n g th e SLINK program (Weeks et al. 1990; Ott 1989). Replicates were analyzed under each of the three diagnostic categories and two inheritance models using the MSIM option of the SLINK program. The proportion of the replicates resulting in lod scores higher than two or three under each model are shown in Table 2. Two out of 5000 replicates gave a lod score $>2.17$ under the AO model and diagnostic category A, for an estimated empir- 
PEKKARINEN EI AL.

ical $P$ value of 0.0004 (upper limit of $95 \%$ confidence interval for the estimated $P$ value is 0.0014). Similarly, 1 out of 5000 unlinked replicates analyzed under the SML model and diagnostic category A resulted in a lod score $>3.54$, for an estimated $P$ value of 0.0002 (upper limit of $95 \%$ confidence interval is 0.0012 ). If all the replicates resulting in lod scores $>3.54$ in the analyses under any of the six diagnostic category and inheritance model combinations were summed, three such replicates were found resulting in a maximized-over-models $P$ value of 0.0006 (upper limit of $95 \%$ confidence interval is 0.0018 ).

Segregation of the X-chromosomal Haplotype in Pedigree P1OI

Haplotypes were constructed using 16 markers between the $\mathrm{m}$ a $\mathrm{r}$ k e r s DXS425 and DXS1227 on the Xq24-q27 region. The restricted haplotype for markers DXS737, D X S 100 , D X S 1114 , HPRT, and DXS 1254 is shown in Figure 2. The $\mathrm{m}$ a $\mathrm{r} k \mathrm{k}$ r DXS994 could

Table 2. Simulation analyses in pedigree P101

\begin{tabular}{|c|c|c|c|c|c|}
\hline \multirow[b]{2}{*}{ Model $^{a}$} & \multirow[b]{2}{*}{ Diagn. ${ }^{b}$} & \multirow[b]{2}{*}{ AMLS $^{c}$} & \multirow[b]{2}{*}{ S.D. ${ }^{d}$} & \multicolumn{2}{|c|}{$p^{e}$} \\
\hline & & & & $>2$ & $>3$ \\
\hline$S$ & A & 0.12 & 0.27 & 0.0034 & 0.0002 \\
\hline M & B & 0.12 & 0.28 & 0.0026 & 0.0006 \\
\hline $\mathrm{L}$ & C & 0.12 & 0.26 & 0.0020 & 0.0004 \\
\hline A & A & 0.13 & 0.26 & 0.0010 & 0.0000 \\
\hline $\mathrm{O}$ & B & 0.13 & 0.26 & 0.0004 & 0.0000 \\
\hline$M$ & $C$ & 0.12 & 0.25 & 0.0000 & 0.0000 \\
\hline \multicolumn{6}{|c|}{$\begin{array}{l}5000 \text { replicates of Pedigree P101 were simulated at the } \Theta=0.5 \text { from the marker } \\
\text { DXS994 using SLINK and then analyzed using MSIM (Weeks et al. 1990; Ott 1989). } \\
\text { aThe inheritance model used in the MSIM analyses: (SML) Single major locus model; } \\
\text { (AOM) affecteds only model (Table 5). } \\
\text { b(Diagn.) The diagnostic category used in the MSIM analyses. } \\
\text { 'Average maximum lod score. } \\
\text { dStandard deviation. } \\
\text { eProbability of a replicate to result in a lod score higher than } 2 \text { or } 3 .\end{array}$} \\
\hline
\end{tabular}

413, and 415 in Fig. 2) or schizoaffective (ID 422) disorder carried the same haplotype. No recombination events were present in the affected individuals in the 20-cM chromosomal region between the markers DXS425 and DXS1227 (Fig. 1), and thus this complete DNA region remains as a potential site for the BP locus in this family. Ten unaffected females (IDs 209, 211, 301, 304, 318, $408,421,423,424$, and 427 in Fig. 2), who were 34-91 years of age, and three unaffected males (IDs 401, 409, and 416), who are 35, 37, and 47 years of age, also carried the same haplotype in this complete chromosomal region and therefore have to represent nonpenetrant carriers. Four females (IDs 403, 404, 411, and 418) carried small portions of the complete haplotype. The location of the disease locus between $\mathrm{m}$ a r k e r s DXS100 and DXS1114 (the distance of about $4 \mathrm{cM}$ ) would result in the smallest $\mathrm{number}$ of nonpenetrant carriers ( $9 \mathrm{fe}$ males and 3 males), and the location in the vicinity of $\mathrm{m}$ a $\mathrm{r}$ k e r s DXS737 and DXS100 would result in the highest number (12 females and 3 males).

not be utilized, because its location is still controversial. In the report from the Fifth International Workshop on Human X Chromosome Mapping 1994 (Willard et al. 1994), it was localized between the markers DXS425 and DXS737, but in several genetic maps it is positioned more distal, between DXS100 and DXS294 (Donnelly et al. 1994; Gyapay et al. 1994; Wang et al. 1994). Unfortunately, our family material was too small to try to resolve its location. The haplotype analysis revealed that all the living family members (or those whose haplotype could be reconstructed) affected by bipolar (IDs 208, 309, 310, 320, 324,

\section{Sequence Analysis of the HPRT Coding Region}

The gene coding for the enzyme HPRT (Stout and Caskey 1989) resides on Xq26, and no obligatory recombination events were observed between the disease and the HPRT locus in Pedigree P101. The coding region of the gene was sequenced from one affected female (ID 309 in Fig. 2) and one unaffected male (ID 414) in Pedigree P101, but no nucleotide variation was observed, when these sequences were compared with the published cDNA sequence (Jolly et al. 1983). 
PREDISPOSING LOCUS TO BIPOLAR DISORDER ON XQ24-Q27.1

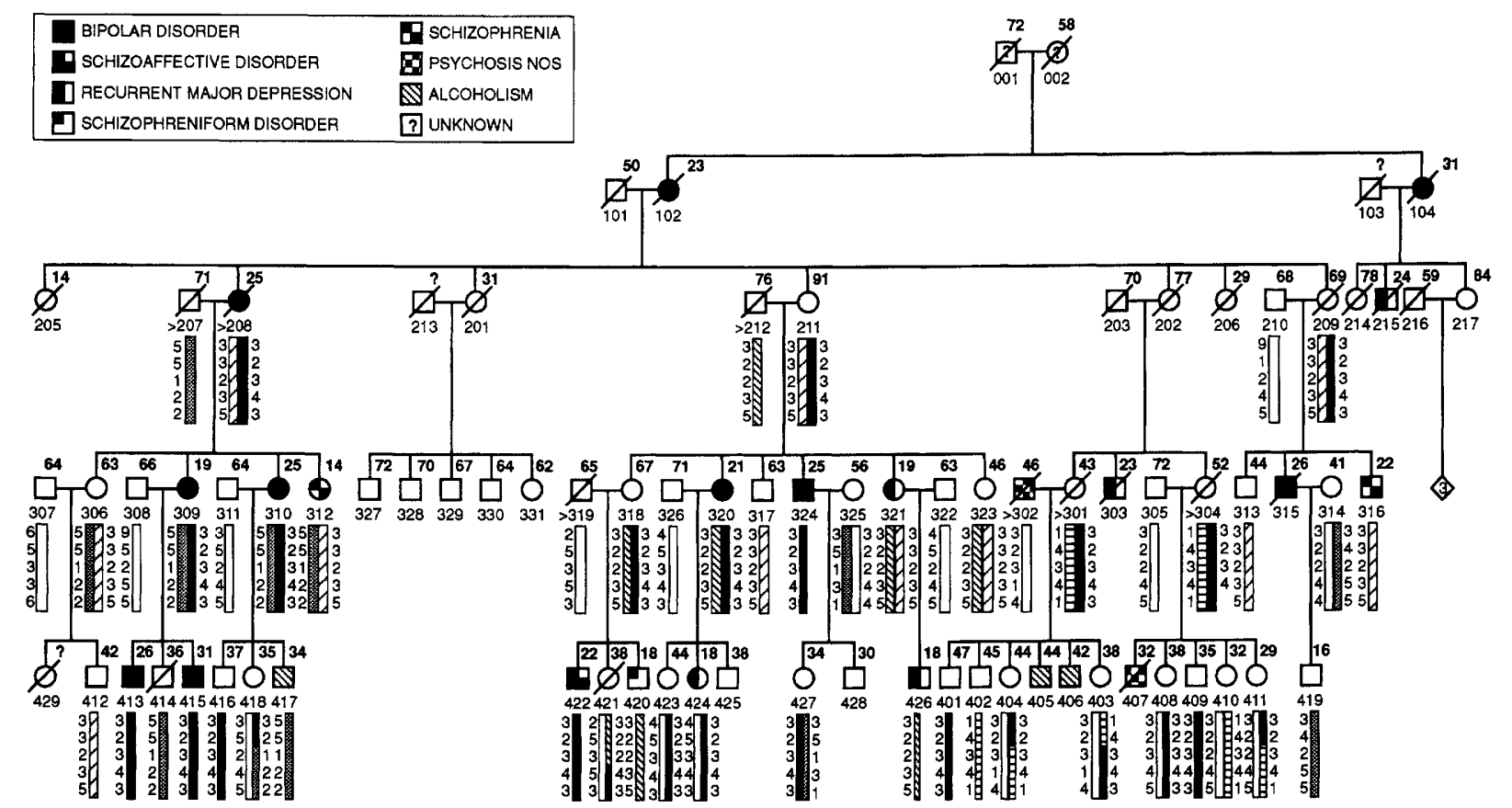

Figure 2 Pedigree P101. Numerals beneath each symbol indicate the identity number for the individual. Numerals in the top right corner of each symbol indicate the age of onset of an affected individual and the age of an unaffected individual at death or at last interview. A question mark indicates that the age at death is unknown. The boxes beneath the identity numbers indicate the haplotypes, and the numbers next to the boxes indicate different alleles for the markers. The order of the genotyped markers from the top is DXS737, DXS100, DXS1114, HPRT, DXS1254. The identity numbers marked with > refer to the individuals whose haplotypes have been reconstructed.

\section{DISCUSSION}

We report here highly suggestive evidence of linkage of $\mathrm{BP}$ to the chromosomal region surrounding the marker DXS994 on Xq24-q26 in a single extended Finnish pedigree both under the SML and the AO models. A lod score of 3.54 was obtained under the most stringent diagnostic category A, in which the individuals with BP (types I and II and NOS) or schizoaffective disorder were considered affected. If the individuals with unipolar disorder were included, the evidence for linkage dropped. Analyses with markers outside the chromosomal region of Xq24-q27.1 resulted in negative lod scores rendering the existence of a susceptibility locus near to the $\mathrm{CB}$ and G6PD loci highly unlikely.

The segregation of $\mathrm{BP}$ in this pedigree is compatible with X-linkage but does not provide unequivocal evidence for $\mathrm{X}$-chromosomal transmission. This is because the first three generations show an excess of females, diminishing the possibility to detect male-to-male transmission. The reproductive rate of the affected males in the ped- igree is low because of their high mortality: In the fourth and fifth generations, two affected males (IDs 303 and 407 in Fig. 2) had committed suicide at a young age before they reproduced and one affected male (ID 315) committed suicide after his first child. The only son of ID 413 died in a car accident. Two affected males in this pedigree have offspring (IDs 324 and 315). Their sons were assessed to be unaffected, but they are still only 30 (ID 428) and 16 (ID 419) years of age.

The lack of evidence for the X-chromosomal transmission of BP has been discussed (Hebebrand 1992). However, segregation analyses in complex diseases are problematic. The segregation ratios presented for an $\mathrm{X}$-linked disease gene for BP are based on assumptions of equal penetrance and reproductive fitness in the sexes, and they do not take into account polygenic interactions, where multiple genetic and environmental factors, none of which may be obligatory to cause disease, could predispose to BP. If one of the predisposing genes would be X-linked dominant, but others were not, it could totally mask the presence of an X-linked gene. Therefore, finding 
the linkage in a complex disease is the best evidence for the existence of a disease locus with major influence.

When the haplotypes were constructed for the Xq24-q27.1 markers (Fig. 2), all the family members with bipolar or schizoaffective disorder were found to carry the same haplotype. This is the first report on linkage of BP, where a distinct haplotype constructed using highly informative DNA markers was found to segregate with $\mathrm{BP}$, excluding a possibility for false linkage owing to undetected recombinations. The smallest number of nonpenetrant carriers would be present if the BP gene would reside in the 4-cM chromosomal region between the markers DXS100 and DXS1114. This restricted haplotype was carried by 13 females, of whom 4 were affected, and 7 males, of whom 4 were affected (estimated from the haplotyped family members). Thus, the penetrance of the susceptibility gene would be $\sim 0.6$ in males and $\sim 0.3$ in females. The largest number of nonpenetrant carriers would be present if the putative disease locus would reside in the vicinity of the markers DXS737 and DXS100. Then, the number of carrier females would be 16 instead of 13 , and the penetrance in females would be 0.25 . This low penetrance can be explained by several factors. Many of the unaffected carriers are at ages where they could still develop the disease, even though all of them have passed the low mean age of onset in this pedigree ( 22 years of age). Inactivation of the defective chromosome (Migeon 1994), such that the deficient allele would be expressed only at a subthreshold percentage of cells, could reduce the penetrance in females. It is also very likely that other genetic or environmental factors are required for the expression of full-blown disease.

Several genes have been identified in the chromosomal region just centromeric to the F9 gene. Among the most interesting ones is the gene for the enzyme HPRT (Stout and Caskey 1989), which catalyzes the metabolic salvage of the purine bases hypoxanthine and guanine. This enzyme is expressed in all tissues at low levels, except for the basal ganglia where the concentration is high. Complete deficiency of HPRT results in Lesch-Nyhan syndrome with severe neuropsychiatric symptoms, but the specific relationship between these symptoms and the HPRT deficiency is unclear. Mostly, the deficiency seems to affect the basal ganglia and their dopaminergic system, and thus the possibility exists that the expression of this gene could also influence mood. With our sequence analyses we excluded a mutation in the coding region of HPRT as a causative mutation for BP in this family.

Our results would seem to support the previous reports of linkage of BP to the F9 gene on Xq26.3 (Mendlewicz et al. 1987; Craddock and Owen 1992; Gill et al. 1992; Lucotte et al. 1992; Jefferies et al. 1993). However, a variety of diagnostic criteria and inheritance models have been adopted in these studies complicating interpretation of their results. It should be stressed that we have studied previously the F9 marker in pedigree P101 in an attempt to replicate or exclude the original finding of linkage by Mendlewicz and colleagues (1987). In this study we adopted the diagnostic criteria of Mendlewicz and colleagues, which included to the same category both unipolar and bipolar disorder, and came to the conclusion of excluding linkage of manic depressive illness to the F9 locus (Bredbacka et al. 1993). We also adopted diagnostic category A including only bipolar I subjects, but the results of the linkage analyses under this category remained uninformative. This is also obvious from Table 1, A and B, of the present study. When a genome screen was started in Pedigree P101, the present diagnostic categories were constructed and more informative markers centromeric to F9 were analyzed, and only then the evidence for linkage appeared. This emphasizes the importance of well-based diagnostic classification and the use of maximally informative markers in the linkage analyses.

Against this background, we were interested to know what would be the results of the studies published previously on bipolar pedigrees typed with Xq26-q27 markers if they were analyzed under uniform diagnostic criteria and inheritance models. Therefore, we carried out a reanalyses where all available pedigrees irrespective of their results were included. These studies and their original results are summarized in Table 3. Linkage analyses were carried out under diagnostic category $\mathrm{A}$, and the $\mathrm{AO}$ model using a polylocus method (Terwilliger and Ott 1993). In this approach, if the locus of interest is uninformative in a pedigree (e.g., not analyzed), the nearest informative marker to the primary locus of interest is analyzed instead to extract linkage information from all pedigrees together in a two-point context. The allele frequencies were taken from Gejman and colleagues (1990). In the reanalyses, suggestive evidence for linkage was found. The 
PREDISPOSING LOCUS TO BIPOLAR DISORDER ON X X24-ф27.1

Table 3. Published data on Xq26-q27 markers in bipolar disorder

\begin{tabular}{|c|c|c|c|}
\hline Reference & $\begin{array}{l}\text { No. of } \\
\text { pedigrees }\end{array}$ & Markers $^{a}$ & Results $^{b}$ \\
\hline $\begin{array}{l}\text { Mendlewizc et al. (1987) } \\
\text { Lucotte et al. (1992) } \\
\text { Jeffries et al. (1993) } \\
\text { Gejman et al. (1990) } \\
\text { Baron et al. (1993) } \\
\text { De bruyn et al. (1994) }\end{array}$ & $\begin{array}{c}11 \\
1 \text { (9) } \\
1\end{array}$ & $\begin{array}{l}\text { F9 } \\
\text { F9 (DXS51, DXS98) } \\
\text { DXS51, F9 (DXS105, DXS98, } \\
\text { DXS369, DXS297) } \\
\text { DXS51, F9, }{ }^{C} \text { DXS105, DXS98 } \\
\text { DXS98 } \\
\text { F9, DXS105 }\end{array}$ & $\begin{array}{l}z=3.10 \text { at } \Theta=0.11 \\
\text { F9: } z=3.91 \text { at } \Theta=0.00 \\
\text { DXS51: } z=1.89 \text { at } \theta=0.00 \\
\text { F9: } z=2.20 \text { at } \theta=0.00 \\
\text { all markers: } z<-2 \\
z<-2 \\
\text { 1. F9: } z=1.12 \text { at } \theta=0.00 \\
\text { DXS105: } z=0.12 \text { at } \theta=0.00 \\
\text { 2. F9: } z<-2 \\
\text { DXS105: } z<-2\end{array}$ \\
\hline \multicolumn{4}{|c|}{$\begin{array}{l}\text { Previously published studies of bipolar pedigrees typed with } X q 26-q 27 \text { markers. Data in the parenthesis could not be reanalyzed, } \\
\text { since not enough details were given. } \\
\text { aMarkers outside the chromosomal region of Xq26-q27 are not shown. } \\
\text { bThe results summarized for } X q 26-q 27 \text { markers. ( } z \text { ) The lod score; } \Theta \text { the recombination fraction. De bruyn and colleagues (1994) } \\
\text { divided their pedigrees into two sets: Set } 1 \text { includes two pedigrees studied previously by Mendlewicz and colleagues and set } 2 \\
\text { includes seven newly ascertained pedigrees. } \\
{ }^{c} \text { Gejman and colleagues (1990) studied three different polymorphisms in the F9 locus. } \\
{ }^{d} \text { Two of these pedigrees were also studied by Mendlewicz and colleagues (1987). }\end{array}$} \\
\hline
\end{tabular}

maximum polylocus lod scores obtained to the markers DXS51, F9a, F9b, DXS105, and DXS98 were $2.78,1.51,1.77,-0.02$, and -0.03 , respectively. Consequently, these combined data from previous studies would also support the linkage of $\mathrm{BP}$ to the Xq26 region, and the evidence for linkage decreases when moving telomeric to F9. We acknowledge, that the possibility for bias in favor of linkage and in favor of small recombination fraction estimates exists, because of the reporting bias in favor of publishing positive results. However, these preliminary data from the reanalyses should encourage investigators who have pedigrees that have previously shown linkage to Xq26, to reanalyze them with updated diagnoses and more informative DNA markers on Xq24-q27.1. This should clarify the question of $\mathrm{X}$-linkage of BP in these pedigrees or in a fraction of them.

Pedigree P101 originates in a district in Eastern Finland, which received its stable Finnish population only in the 17 th century and experienced the major population expansion even later (for review, see de la Chapelle 1993). Many of the rare recessive disorders, which are much more prevalent in Finland than elsewhere in the world (the Finnish disease heritage), are encountered in this region (Norio et al. 1973). We have some preliminary data, that BP could be more preva- lent in Eastern parts than elsewhere in Finland suggesting that some genes predisposing to BP could be enriched in this region. This kind of population is very useful for linkage disequilibrium mapping. Therefore, our next approach is to study the bipolar patients originating in this restricted area of Finland. The finding of an enrichment of a distinct haplotype on Xq24-q27.1 in this patient population would both confirm our preliminary evidence for linkage and enable us to further restrict the critical region on the $\mathrm{X}$ chromosome. In this process also, the marker data from families around the world will be highly useful and will provide the starting point for solving the significance of this chromosomal region in predisposition to $\mathrm{BP}$.

\section{METHODS}

\section{Clinical Assessment of Pedigree P101}

Pedigree P101 (presented in Fig. 2) has been described earlier by Bredbacka and colleagues (1993). It was ascertained through a proband (ID 309 in Fig. 2) in a psychiatric hospital in Eastern Finland. Diagnostic information was gathered on each pedigree member by at least two interviews by a psychiatrist (P.-E.B.) using the Finnish translation of SADS-L (Endicott and Spitzer 1978) and by an extensive search to the medical records and church registers. Causes of death were ascertained by forensic examinations and by 
PEKKARINEN ET AL.

additional interviews of relatives and neighbors. On the basis of these data, a case record was made by the interviewer on each affected pedigree member, and these records were introduced to a senior psychiatrist (J.L.), who made his independent diagnoses. The two psychiatrists (P.-E.B. and J.L.) made together the final consensus diagnoses on the basis of all available data according to DSMIII-R (American Psychiatric Association 1987) and without knowledge of the genotypic data. Further support for them was received by gathering data on family members' hospitalizations, hospital discharge diagnoses, and free medication from the National Hospital Discharge and Social Insurance registers. The mental health status of those individuals, who provided DNA samples, has been carefully followed already 7 years (P.E.B.) by interviews, phone calls and contacts to local outpatient clinics. During this followup time, one family member became affected by bipolar disorder I (ID 415 in Fig. 2) and another, who had suffered single episode of depression, turned out to have recurrent major depression (ID 321 in Fig. 2). The study protocol has been approved by the ethical committee of the National Public Health Institute, and all the blood samples were taken in accordance with the Helsinki declaration.

A psychiatric disorder was diagnosed on 24 family members according to DSM-III-R: 10

Table 4. Analyzed X-chromosomal markers

\begin{tabular}{llll}
\hline Locus & Marker & Het. $^{\mathbf{a}}$ & GDB ID \\
\hline DXS1001 & AFM248we5 & 0.82 & G00-188-531 \\
DXS425 & $861 / 862$ & 0.79 & G00-171-211 \\
DXS737 & MS120 & 0.60 & G00-182-659 \\
DXS1122 & 26AD & 0.35 & G00-196-549 \\
DXS100 & 23.4AC & 0.59 & G00-316-892 \\
DXS994 & AFM205wd2 & 0.68 & G00-188-323 \\
DXS1114 & ACAG/TGTC & 0.59 & G00-192-946 \\
HPRT & HPRTB & 0.77 & G00-212-631 \\
DXS1254 & MFD207 & 0.79 & G00-215-019 \\
DXS300 & DXS300.PCR & 0.40 & G00-181-502 \\
DXS1062 & AFM207xb8 & 0.74 & G00-189-395 \\
DXS294 & DXS294.PCR & 0.75 & G00-181-501 \\
DXS1192 & AFM196xa1 & 0.84 & G00-199-152 \\
DXS102 & DXS102.PCR & 0.71 & G00-181-092 \\
F9 & pVIII & 0.45 & G00-164-160 \\
DXS984 & AFM105xC5 & 0.72 & G00-187-979 \\
DXS1227 & AFM317ye9 & 0.73 & G00-200-332 \\
DXS292 & VK14 & 0.58 & G00-182-422 \\
DXS1200 & AFM254wh1 & 0.65 & G00-199-554 \\
DXS548 & RS46-CA & 0.65 & G00-177-918 \\
DXS1193 & AFM199wC7 & 0.75 & G00-199-170 \\
DXS1113 & AGTG/TCAC & 0.76 & G00-192-945 \\
GABRA3 & MGD341/342 & 0.36 & G00-180-413 \\
DXS15 & 9120/9121 & 0.84 & G00-207-346 \\
F8 & 2A/intron13-1A & 0.69 & G00-185-865 \\
\hline aHeterozygosity. & & & \\
bThe GDB (Genome Database) identity number. & \\
\hline & & & \\
\hline
\end{tabular}

with a BP [8 type I, 1

type II, and 1 bipolar

NOS (not otherwise specified)], 1 with schizoaffective disorder of bipolar type, 5 with recurrent major depression, 2 with schizophrenia, 1 with schizophreniform disorder, 2 with psychosis NOS, and 3 with alcohol abuse (Fig. 2). Two family members refused to participate in the study (IDs 425 and 428 in Fig. 2) and two family members could not be reached (IDs 405 and 406 in Fig. 2). These individuals were excluded from the analyses. Because the segregation of $\mathrm{BP}$ in this pedigree was compatible with an X-chromosomal locus, the affected family members were also examined for differences in the clinical picture between the sexes, but no major deviations were found in the symptomatology, age of onset, or the number or duration of the disease episodes.

\section{Marker Genotypings in Pedigree P1OI}

Genomic DNA was extracted from venous blood samples using the standard protocol (Vandenplas et al. 1984). The details for the 25 markers typed in Pedigree P101 are shown in Table 4.

All the amplifiable markers (except F9) were analyzed using PCR and denaturating polyacrylamide gel electrophoresis (PAGE). One of the PCR primers was labeled with ${ }^{32} \mathrm{P}$ at the $5^{\prime}$ end using $\left[\gamma_{-}^{32} \mathrm{P}\right] \mathrm{ATP}$ and T4 polynucleotide kinase. A PCR reaction included $20 \mathrm{ng}$ of human genomic DNA, 2-15 pmoles of each primer, $0.2 \mathrm{~mm}$ of the dNTPs, and 0.15 units of Taq polymerase in $15 \mu \mathrm{l}$ of its buffer. The PCR reactions were performed in multiwell microtiter plates for 26 cycles with $30 \mathrm{sec}$ of denaturation at $95^{\circ} \mathrm{C}, 30 \mathrm{sec}$ of annealing at specific temperature for each primer pair, and 30 sec of elongation at $72^{\circ} \mathrm{C}$. The initial denaturation was extended to $3 \mathrm{~min}$, and the final elongation to $5 \mathrm{~min}$. The amplified products were electrophoresed through a $5 \%$ polyacrylamide sequencing gel, and the gel was dried and subjected to autoradiography.

The restriction fragment length polymorphism in the F9 locus was analyzed as described by Bredbacka and colleagues (1993).

\section{Linkage Analyses in Pedigree P10I}

Because the phenotypic expression of the genes predisposing to $\mathrm{BP}$ has not been established, the linkage analyses were performed in three separate diagnostic categories: (A) 
PREDISPOSING LOCUS IO BIPOLAR DISORDER ON X

Table 5. Liability classes and gene frequencies

\begin{tabular}{clllll}
\hline & \multicolumn{5}{c}{ Genotype } \\
\cline { 2 - 6 } Age $^{\mathbf{a}}$ & $\mathbf{D D}^{\mathbf{b}}$ & $\mathbf{D d}^{\mathbf{c}}$ & $\mathbf{d d}^{\mathbf{A} \mathbf{d}}$ & $\mathbf{d d}^{\mathbf{B ~ d}}$ & $\mathbf{d d}^{\mathbf{C} \mathbf{d}}$ \\
\hline $0-14$ & 0.025000 & 0.025000 & 0.000014 & 0.000080 & 0.000200 \\
$15-24$ & 0.225000 & 0.225000 & 0.000122 & 0.000719 & 0.001800 \\
$25-34$ & 0.600000 & 0.600000 & 0.000326 & 0.001980 & 0.004800 \\
$35 \rightarrow$ & 0.800000 & 0.800000 & 0.000434 & 0.002556 & 0.006400 \\
\multicolumn{2}{l}{ Gene frequencies: } & & 0.006 & 0.011 & 0.015 \\
\hline
\end{tabular}

The penetrances and disease gene frequencies used under the single major locus model. In the affecteds only model the penetrances were divided by 1000 .

The age of an individual in the linkage analyses at the time of the last interview or at death.

b(D) The disease allele.

${ }^{c}(d)$ The healthy allele.

${ }^{d}(A, B$, and C) Different diagnostic categories. ham et al. 1993)

and the simulation analyses by the SLINK program (Ott 1989; Weeks et al. 1990). The allele frequencies of the markers were either calculated from 73 unrelated Finns ( D X S 737 , D X S 100 D X S 11122 , D X S 994 , DX S 1114 , HPRT) or estimated from 12 married-in persons in the pedigree. bipolar disorder type I, type II, and type NOS and schizoaffective disorder, manic type, (B) in addition to category A, recurrent major depression, and $(\mathrm{C})$ in addition to category B, schizophrenia, schizophreniform disorder, and psychosis NOS.

Because the mode of inheritance of the susceptibility to $\mathrm{BP}$ has not been resolved, two different models were constructed for the statistical analyses of the genotypic data. A SML model was based on the hypothesis of one major gene with incomplete and age-dependent penetrance causing psychiatric illnesses in Pedigree P101. The absence of male-to-male transmission of the disease was compatible with X-chromosomal transmission and the appearence of $\mathrm{BP}$ in females favored dominant transmission. The values for penetrance and disease gene frequency were adapted to the estimates of prevalence and monozygotic twin concordance in the three diagnostic categories so that the disease gene frequency and the phenocopy rate increase from category A to $C$. Age-dependent penetrance classes were constructed from the ages of onset of all psychiatrically ill individuals on Pedigree P101 (the differences between the age-of-onset curves in the three diagnostic categories were nonsignificant) as described by Ott (1991). A small possibility for sporadic cases was allowed, but the model predicts that $96 \%, 88 \%$, and $79 \%$ of the affected individuals carry the same disease gene in the diagnostic categories A, B, and C, respectively. The liability classes and disease gene frequencies are presented in Table 5 .

The second approach taken was the AO model, which allows for an epistatic effect of several disease genes. In this situation many unaffected individuals possess the diseasepredisposing genotype at one of the susceptibility loci but lack the second disease locus genotype required for the development of the disease. In the AO analyses, the disease status of unaffected individuals is considered unknown and the genotypic information on the disease locus is only derived from the affected individuals. This is accomplished by dividing the penetrances in Table 5 by 1000 .

The two-point linkage analyses were carried out by using the LINKAGE package (Lathrop et al. 1984; Cotting-

\section{Sequencing of the HPRT Coding Region}

Total RNA was extracted from lymphoblast cell cultures using the standard protocol (Chirgwin et al. 1979). The hypoxanthine phosphoribosyl transferase (HPRT) cDNA (Jolly et al. 1983) was synthesized using AMV reverse transcriptase and a primer 5'-CTC-CAG-ATG-TTT-CCA-AACTCA-AC-3' (3551). The cDNA was amplified by PCR in a reaction volume of $50 \mu \mathrm{l}$ containing one-tenth of the reverse transcriptase reaction mixture, 50 pmoles of each primer, $0.2 \mathrm{~mm}$ mixture of dNTPs, $5 \%$ dimethylsulfoxide, and 1 unit of Taq DNA polymerase in its buffer. The PCR consisted of 26 cycles of $30 \mathrm{sec}$ of denaturation at $95^{\circ} \mathrm{C}, 30$ sec of annealing at $60^{\circ} \mathrm{C}$, and $45 \mathrm{sec}$ of elongation at $72^{\circ} \mathrm{C}$ except for the initial denaturation of $3 \mathrm{~min}$ and the last elongation of $5 \mathrm{~min}$. The PCR primers used were 3551, which was 5'-biotin-labeled during it's synthesis, and 5'TCC-TGA-GCA-GTC-AGC-CCG-CG-3' (3523). The HPRT cDNA was sequenced in three overlapping fragments using solid-phase sequencing (Syvänen et al. 1989) with the sequencing primers $3523,5^{\prime}$-ACA-TTG-TAG-CCC-TCT-GTGTG-3' (3525), and 5'-TGA-CAC-TGG-CAA-AAC-AAT-GCAG-3' (3524). The sequencing products were electrophoresed through a $5 \%$ denaturating polyacrylamide gel; the gel was dried and subjected to autoradiography.

\section{ACKNOWLEDGMENTS}

We are indebted to the family members for their patience and cooperation. We heartily thank Drs. Tiina Paunio, Anu Wartiovaara, and Ann-Christine Syvänen for their critical reading of the manuscript. The grants from the Jalmari and Rauha Ahokas Foundation and the Sigrid Juselius Foundation in Finland, and the grants from the National Association for Research on Schizophrenia and Depression, the National Center for Human Genome Research (HG00008) and the National Institute of Mental Health (44292) in the USA are appreciated.

The publication costs of this article were defrayed in part by payment of page charges. This article must therefore be hereby marked "advertisement" in accordance with 18 USC section 1734 solely to indicate this fact. 


\section{PEKKARINEN ET AL.}

\section{REFERENCES}

American Psychiatric Association. 1987. Diagnostic and statistical manual of mental disorders, 3rd ed., revised. American Psychiatric Association, Washington, DC.

Baron, M. 1977. Linkage between an X-chromosome marker (deutan color blindness) and bipolar affective illness. Arch. Gen. Psychiatry 34: 721-725.

Baron, M., N. Risch, R. Hamburger, B. Mandel, M. Kushner, M. Newman, D. Drumer, and R.H. Belmaker. 1987. Genetic linkage between X-chromosome markers and bipolar affective illness. Nature 326: 289-292.

Baron, M., N.F. Freimer, N. Risch, B. Lerer, J.R. Alexander, R.E. Straub, S. Asokan, K. Das, A. Peterson, J. Amos, J. Endicott, J. Ott, and T.C. Gilliam. 1993. Diminished support for linkage between manic depressive illness and X-chromosome markers in three Israeli pedigrees. Nature Genet. 3: 49-55.

Berrettini, W.H., L.R. Goldin, J. Gelernter, P.V. Gejman, E.S. Gershon, and S. Detera-Wadleigh. 1990.

$\mathrm{X}$-chromosome markers and manic-depressive illness. Rejection of linkage to $\mathrm{Xq} 28$ in nine bipolar pedigrees. Arch. Gen. Psychiatry 47: 366-373.

Bredbacka, P.-E., P. Pekkarinen, L. Peltonen, and J. Lönnqvist. 1993. Bipolar disorder in an extended pedigree with a segregation pattern compatible with $\mathrm{X}$-linked transmission: Exclusion of the previously reported linkage to F9. Psychiatr. Genet. 3: 79-87.

Chirgwin, J.M., A.E. Przybyla, R.J. MacDonald, and W.J. Rutter. 1979. Isolation of biologically active ribonucleic acid from sources enriched in ribonuclease. Biochemistry 18: 5294-5299.

Cottingham, R.W. Jr., R.M. Idury, and A.A. Schaffer. 1993. Faster sequential genetic linkage computations. Am. J. Hum. Genet. 53: 252-263.

Craddock, N. and M. Owen. 1992. Christmas disease and major affective disorder. Br. J. Psychiatry 160: 715.

De bruyn, A., P. Raeymaekers, K. Mendelbaum, L.A. Sandkuijl, G. Raes, V. Delvenne, D. Hirsch, L. Staner, J. Mendlewicz, and C. Van Broeckhoven. 1994. Linkage analysis of bipolar illness with X-chromosome DNA markers: A susceptibility gene in Xq27-q28 cannot be excluded. Am. J. Med. Genet. 54: 411-419.

de la Chapelle, A. 1993. Disease gene mapping in isolated human populations: The example of Finland. $J$. Med. Genet. 30: 857-865.

Del Zompo, M., A. Bocchetta, L.R. Goldin, and G.U. Corsini. 1984. Linkage between X-chromosome markers and manic-depressive illness: Two Sardinian pedigrees. Acta Psychiatr. Scand. 70: 282-287.

Donnelly, A., H. Kozman, A.K. Gedeon, S. Webb, M. Lynch, G.R. Sutherland, R.I. Richards, and J.C. Mulley.
1994. A linkage map of microsatellite markers on the human X chromosome. Genomics 20: 363-370.

Endicott, J. and R.L. Spitzer. 1978. A diagnostic interview: The schedule for affective disorders and schizophrenia. Arch. Gen. Psychiat. 35: 837-844.

Gejman, P.V., S. Detera-Wadleigh, M.M. Martinez, W.H. Berrettini, L.R. Goldin, J. Gelernter, W.-T. Hsieh, and E.S. Gershon. 1990. Manic depressive illness not linked to factor IX region in an independent series of pedigrees. Genomics 8: 648-655.

Gershon, E.S. and S. Matthysse. 1977. X-linkage: Ascertainment through doubly ill probands. J. Psychiatr. Res. 13: 161-168.

Gershon, E.S., S.D. Targum, S. Matthysse, and W.E. Bunney, Jr. 1979. Color blindness not closely linked to bipolar illness. Arch. Gen. Psychiatr. 36: 1423-1431.

Gershon, E.S., J. Mendlewicx, M. Gastpar, P. Bech, L.R. Goldin, P. Kielholz, O.J. Rafaelsen, F. Vartanian, and W.E. Bunney Jr. 1980. A collaborative study of genetic linkage of bipolar manic-depressive illness and red/green colorblindness. Acta Psychiatr. Scand. 61: 319-338.

Gill, M., D. Castle, and C. Duggan. 1992. Cosegregation of Christmas disease and major affective disorder in a pedigree. Br. J. Psychiatry 160: 112-114.

Goodwin, F.K. and K.R. Jamison. 1990. Manic-depressive illness. Oxford University Press, Oxford, UK.

Gyapay, G., J. Morissette, A. Vignal, C. Dib, C. Fizames, P. Millasseau, S. Marc, G. Bernardi, M. Lathrop, and J. Weissenbach. 1994. The 1993-94 Genethon human genetic linkage map. Nature Genet. 7: 246-339.

Hebebrand, J. 1992. A critical appraisal of X-linked bipolar illness. Br. J. Psychiatry 160: 7-11.

Jeffries, F.M., A.L. Reiss, W.T. Brown, D.A. Meyers, A.C. Glicksman, and S. Bandyopadhyay. 1993. Bipolar spectrum disorder and fragile $\mathrm{X}$ syndrome: A family study. Biol. Psychiatry 33: 213-216.

Jolly, D.J., H. Okayama, P. Berg, A.C. Esty, D. Filpula, P. Bohlen, G.G. Johnson, J.E. Shively, T. Hunkapillar, and T. Friedmann. 1983. Isolation and characterization of a full-length expressible cDNA for human hypoxanthine phosphoribosyltransferase. Proc. Natl. Acad. Sci. 80: $447-481$.

Lathrop, G.M., J.-M. Lalouel, C.A. Julier, and J. Ott. 1984. Strategies for multilocus linkage analysis in humans. Proc. Natl. Acad. Sci. 81: 3443-3446.

Lucotte, G., A. Landoulsi, S. Berriche, F. David, and M.C. Babron. 1992. Manic depressive illness is linked to factor IX in a French pedigree. Ann. Genet. 35: 93-95.

Mendlewicz, J. and J.L. Fleiss. 1974. Linkage studies with $\mathrm{X}$-chromosome markers in bipolar (manic-depressive) 


\section{PREDISPOSING LOCUS TO BIPOLAR DISORDER ON XQ24-Q27.I}

and unipolar (depressive) illnesses. Biol. Psychiatry 9: 261-294.

Mendlewicz, J., J.L. Fleiss, and R.R. Fieve. 1972. Evidence for X-linkage in the transmission of manic-depressive illness. J. Am. Med. Assoc. 222: 1624-1627.

Mendlewicz, J., P. Linowski, J.J. Guroff, and H.M. Van Praag. 1979. Colour blindness linkage to bipolar manic depressive illness: New evidence. Arch. Gen. Psychiatry 36: 1442-1447.

Mendlewicz, J., P. Linkowski, and J. Wilmotte. 1980. Linkage between glucose-6-phosphate-dehydrogenase deficiency and manic-depressive psychosis. $\mathrm{Br}$. J. Psychiatry 137: 337-342.

Mendlewicz, J., P. Simon, S. Sevy, F. Charon, H. Brocas, S. Legros, and G. Vassart. 1987. Polymorphic DNA marker on X-chromosome and manic depression. Lancet 1: $1230-1232$.

Migeon, B. 1994. X-chromosome inactivation: Molecular mechanisms and genetic consequences. Trends Genet. 10: $230-235$.

Norio, R., H.R. Nevanlinna, and J. Perheentupa. 1973. Hereditary diseases in Finland; rare flora in rare soil. Ann. Clin. Res. 5: 109-141.

Nurnberger, J.I. and E.S. Gershon. 1992. Genetics. In Handbook of affective disorders (ed. E.S. Paykel), 2nd ed., pp. 131-148. Churchill Livingstone, Edinburgh, UK.

O'Donovan, M.C. and M.J. Owen. 1992. Advances and retreats in the molecular genetics of major mental illness. Ann. Med. 24: 167-173.

Ott, J. 1989. Computer-simulation methods in human linkage analysis. Proc. Natl. Acad. Sci. 86: 4175-4178.

1991. Analysis of human genetic linkage, revised ed. The Johns Hopkins University Press, Baltimore, MD and London, UK.

Reich, T., P.J. Clayton, and G. Winokur. 1969. Family history studies: V. The genetics of mania. Am. J. Psychiatry 125: 1358-1369.

Stout, T.J. and T.C. Caskey. 1989. Hypoxanthine phosphoribosyltransferase deficiency: The Lesch-Nyhan syndrome and gouty arthritis. In The metabolic basis of inherited disease (ed. C.R. Scriver, A.L. Beaudet, W.S. Sly, and D. Valle), pp. 1007-1028. McGraw-Hill. Inc., New York.

Syvänen, A.-C., K. Aalto-Setälä, K. Kontula, and H. Söderlund. 1989. Direct sequencing of affinity-captured amplified human DNA: Application to the detection of apolipoprotein E polymorphism. FEB 258: 71-74.

Terwilliger, J.D. and J. Ott. 1993. A novel polylocus method for linkage analyses using the lod-score or affected sib-pair method. Genet. Epidemiol. 10: 477-482.
Vandenplas, S., I. Wiid, A. Grobler-Rabie, K. Brebner, M. Ricketts, G. Wallis, A. Bester, C. Boyd, and C. Mathew. 1984. Blot hybridisation analysis of genomic DNA. J. Med. Genet. 21: 164-172.

Wang, L.H., A. Collins, S. Lawrence, B.J. Keats, and N.E. Morton. 1994. Integration of gene maps: Chromosome X. Genomics 22: 590-604.

Weeks, D.E., J. Ott, and G.M. Lathrop. 1990. SLINK: A general simulation program for linkage analyses. Am. J. Hum. Genet. (Suppl.) 47: A204.

Weissman, M.M., E.S. Gershon, K.K. Kidd, B.A. Prusoff, J.F. Leckman, E. Dibble, J. Hamovit, W.D. Thompson, D.L. Pauls, and J.J. Guroff. 1984. Psychiatric disorders in the relatives of probands with affective disorders. Arch. Gen. Psychiatry 41: 13-21.

Willard, H.F., F. Cremers, J.L. Mandel, A.P. Monaco, D.L. Nelson, and D. Schlessinger. 1994. Report of the Fifth International Workshop on Human X Chromosome Mapping 1994. Heidelberg, Germany, April 24-27 1994. Cytogenet. Cell Genet. 67: 295-358.

Winokur, G., W. Coryell, M. Keller, J. Endicott, and A. Leon. 1995. A family study of manic-depressive (bipolar I) disease. Is it a distinct illness separable from primary unipolar depression? Arch. Gen. Psychiatry 52: 367- 373. 


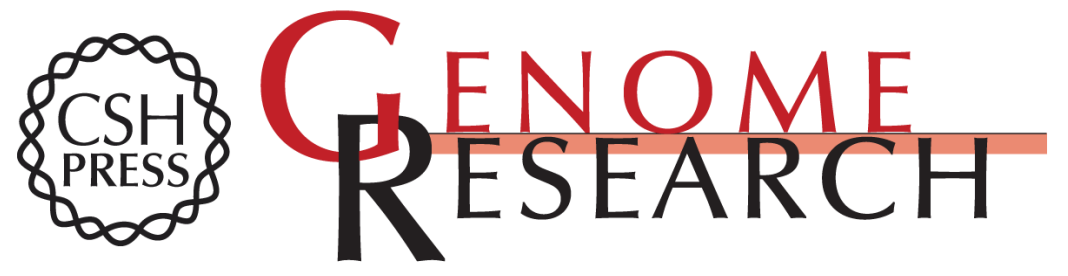

\section{Evidence of a predisposing locus to bipolar disorder on Xq24-q27.1 in an extended Finnish pedigree.}

P Pekkarinen, J Terwilliger, P E Bredbacka, et al.

Genome Res. 1995 5: 105-115

Access the most recent version at doi:10.1101/gr.5.2.105

References This article cites 42 articles, 7 of which can be accessed free at:

http://genome.cshlp.org/content/5/2/105.full.html\#ref-list-1

\section{License}

Email Alerting Receive free email alerts when new articles cite this article - sign up in the box at the Service top right corner of the article or click here.

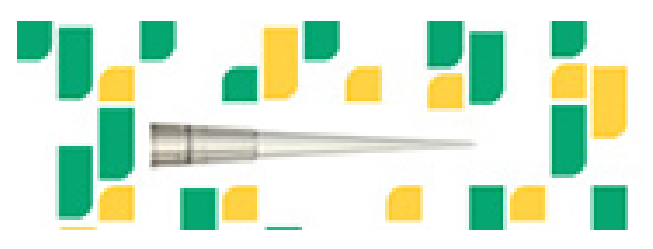

To subscribe to Genome Research go to: https://genome.cshlp.org/subscriptions 